\title{
Perspectives for application of moulded sorption materials based on peat and mineral compositions
}

\author{
Oleg Misnikov ${ }^{1}$ \\ ${ }^{1}$ Tver State Technical University, A. Nikitin Street, 22, 170026, Tver, Russia
}

\begin{abstract}
The paper discusses scientific and technological grounds for using peat, its wastes and processing products as sorption materials for liquidation of pollutions on water and oil basis. A negative effect on the hydro-physical properties of peat by hysteresis phenomena occurring during drying is noted. Use of optimal concentrations of mineral hydrophilic additives in peat matrix allows to increase speed and capacity of sorption. A working hypothesis is proposed that explains the physical and chemical mechanism for increasing quality of composite sorbents. A principal technological scheme for obtaining sorption materials based on peat is developed. It allows to take into account possible transitions between stages of the technological process, which reduce its cost.
\end{abstract}

\section{Introduction}

Various types of sorption materials are widely used for purification of liquid and gaseous mixtures, as well as for selective extraction of pollution agents from solutions. Currently, depending on the requirements for the process of sorption, synthetic and natural materials are used, as well as various types of processing wastes. Peat as a natural sorbent and a raw material occupies a special place among them [1-3]. It is due to the variety of raw material resources, as well as its unique physical and chemical properties.

Organic matter of peat has the ability to form bonds between water molecule and the material by means of hydrogen, ion-dipole, dipole-dipole interactions. Weak interactions can be carried out with aromatic sections and sections with unsaturated bonds. This occurs due to unpaired electrons present in them and due to the Van der Waals forces. The microstructure of native peat associates is responsible for the amount of physico-chemically and osmotically bound water.

Moisture can be absorbed and retained in peat by the following types of bonds:

1. Chemically bound water (crystalized water of mineral part of water). Its binding energy is $40-400 \mathrm{KJ} / \mathrm{mol}$.

2. Physico-chemically bound water. Its binding energy depends on the amount of absorbed water. The water of monosorption is most strongly bound, its amount ranges from 0.15 to $0.2 \mathrm{~kg}$ of water per $1 \mathrm{~kg}$ of dry matter (hereinafter we will use the dimension - $\mathrm{kg} / \mathrm{kg}$ for simplicity). The total amount of moisture of this category in peat can be $0.45-0.55 \mathrm{~kg} / \mathrm{kg}$.

3. Entropy-bound water (retained by osmotic forces). Its binding energy is up to 2 
$\mathrm{KJ} / \mathrm{mol}$. The moisture content of peat in the presence of moisture of this category reaches $1.0-1.4 \mathrm{~kg} / \mathrm{kg}$.

4. Water of mechanical retention. This category includes capillary, immobilized, intracellular and structurally trapped water. The main share is accounted for capillary moisture, the binding energy of which is about $1 \mathrm{KJ} / \mathrm{mol}$.

Absorption of moisture by peat and sorbents on its basis is a reverse (in relation to drying) process. The properties of the material to absorb different types of sorbates is determined by its porosity as well as by the nature of its binding centers. The filling mechanism can be different as the pores can be of three types: macropores, mesopores (transitional) and micropores. There are all types of pores in peat $[4,5]$. In addition, peat systems have a large number of functional groups.

The main indicator, which makes it possible to assess absorbing capacity of peat is its total moisture capacity $\left(\mathrm{W}_{\mathrm{t}}\right)$. The total moisture capacity of peat is affected by its current moisture content and decomposition degree $\left(R_{p}\right)$. But extraction and subsequent drying of peat significantly reduce the value of the total moisture capacity. This is due to oxidation processes during drying and air sorption on structural elements [6]. The effect of partial hydrophobization during peat drying is manifested to a greater degree in systems with a low concentration of mineral components (peat ash).

At the end of the drying process, the physico-chemical water bound to the functional groups is removed [7]. In this case, conditions are created for interactions between macromolecules of organic matter due to hydrogen bonds and through polyvalent cations. The change in the structural characteristics of the material leads to a decrease in the immobilization capacity of the associates of macromolecules. Subsequent water treatment of peat partially splits the hydrogen bonds between the macromolecules. Thus, vacancies are formed for its sorption on functional groups.

The effect of dehydration degree on the reversibility of hydro-physical properties increases with increasing content of humic substances in peat [3]. Another important factor in reducing the water absorption of peat is its mechanical processing. Peat dispersion increases its physical and chemical activity. This entails a decrease in the hydrophilic properties of peat processing products.

In addition to the absorption of water-based pollution, hydrophobic sorbents capable of absorbing oil, its products and waste processing products are of great interest. Such sorbents must absorb a large amount of oil products, remain on water surface for a long time, be easy for collection and recycling. Analysis of conducted studies [8] showed that the characteristics of peat sorbents are sufficient to compete with other sorption materials.

Among non-organic sorbents scientists distinguish clays and diatomites due to their comparatively low cost. Quartz sand is also used for liquidation (sanding-up) small oil spills on land. However, non-organic sorbents have a low absorption capacity (about $0.5 \mathrm{~kg}$ of oil / $\mathrm{kg}$ of sorbent), they do not retain light oils, and when oil spills are liquidated on water they sink together with absorbed oil products.

Natural organic and organo-mineral materials are the most promising type of sorbents for the elimination of oil-based contaminant. The first task to be done on the stage of justification of the technology for obtaining sorbents is the choice of the raw material base. The main indicators that determine the properties of peat raw materials are a deposit type and decomposition degree. Therefore, the initial evaluation of the sorption properties was carried out according to these characteristics. In practice, other approaches are also used: according to the composition of peat-forming plants, the component composition, mineral elements of ash, etc. [9].

Domestic and international experience of production and use of peat sorbents [10-14] demonstrates that the most suitable type of raw material is the upper sphagnum peat of low degree of decomposition. Hence, the primary regulation of the sorption properties of peat is 
carried out by selecting the material with the largest content of least decomposed plant residues. Technological operations during peat extraction disperses its particles. This has a negative effect on the absorption capacity. Therefore, it is necessary to develop extraction technologies that would minimize mechanical effect on the primary peat structure.

Another advantage of peat raw material is its good plasticity and, accordingly, its ability to mould. The main binding components of peat are humic substances. Therefore, when processing peat of low degree of decomposition, their small content does not allow obtaining high-quality moulded products. To solve this problem, various plasticizing substances (clays, organo-mineral deposits, bitumens, gypsum) and other methods for increasing mouldability of peat are used.

Clay modifiers not only increase plasticity of a formed organo-mineral material, but also significantly reduce the hysteresis phenomena in peat, which appears upon its drying. They do not have a significant effect on the porous structure, but due to physical and chemical interactions of the components, a preliminary modification of the composition occurs. Usually, metal salts and oxides, silicones, halogen compounds of zinc, aluminium, magnesium and iron are used as modifiers of carbon fibers. They serve as structuring agents, and also affect the kinetics of pyrolysis (if it is necessary to conduct it).

\section{Method used}

There are two basic methods of sorbents moulding: cylindrical extrusion and pelletizing with disk or drum granulators. In the work to obtain sorbents, the pelletizing method was used, which made it possible to obtain sorbents of spherical shape. The process of moulding by the pelletizing on a disk granulator consisted of four main stages:

1. mixing of the particles of source dispersed material with the particles of additives (in our case, mineral clay inclusions) and binding components;

2. formation of granules from fine particles and destruction of large lumps;

3. pelletizing, consolidation and compaction of granules as a result of their movement along the surface of the disk;

4. strengthening of bonds and stabilization of granule structure.

In peat and mineral compositions, water together with clay inclusions served as a binding material at the initial stage of moulding. They helped to accelerate the process of granule formation of mixtures with relatively low initial humidity. In the processes that we consider, granule formation and structural changes during the subsequent drying of the granules occurred due to hydrogen and Van der Waals interactions. It is known that peat contains mainly hydrophilic compounds, but part of its organic matter is composed of hydrophobic components. The increase in the hydrophilicity of organic systems in our case was accomplished by adding clay additives (dispersed kaolin clay).

In the moulded organic-containing mixtures, moisture content of the main component (peat) was $w \approx 65-75 \%$, depending on $\mathrm{R}_{\mathrm{T}}$. At lower values of $w$, additional time was required to absorb moisture. Partial hydrophobicity of peat, acquired by it during drying, affected here. During the movement, the granules were compacted by impactrotational motion along the fixed material layer and along the board (bottom) of the disk of the granulator. At the same time, a less wet loose material adhered to the surface of the appearing pellet. The lumps of material were compacted as a result of repeated impacts and interspersion.

The granules obtained by this method were separated into fractions using sieves and dried at temperature $T=80^{\circ} \mathrm{C}$ till constant weight. In a number of experiments, the dried pellets were additionally subjected to thermal exposure without access to oxygen at higher temperatures $\left(T \approx 300^{\circ} \mathrm{C}\right)$. 


\section{Results and Discussion}

Clay materials are hydrophilic and possess ion exchangeability. They absorb moisture almost immediately compared to peat. This is due to the fact that the main structural hydroxyl groups ( $\mathrm{OH}^{-}$crystalline faces) of minerals are free. Therefore, they have the ability to form hydrogen bonds with water molecules [4]. At the same time, a relatively small waterabsorbing ability of clays does not ensure their use as effective sorption materials. The use of peat and mineral compositions allows to strengthen an insufficient hydrophilicity in the peat matrix, as well as sorption capacity in the clay material.

Experiments with sorbents obtained from various types of peat and compositions based on them demonstrated that the additions of clay material (kaolin clay) do not reduce (which was assumed a priori), but rather increase sorption capacity of the granules. At the same time, there is a persistent tendency to intensify the process of moisture absorption by the compositions (Figure 1).

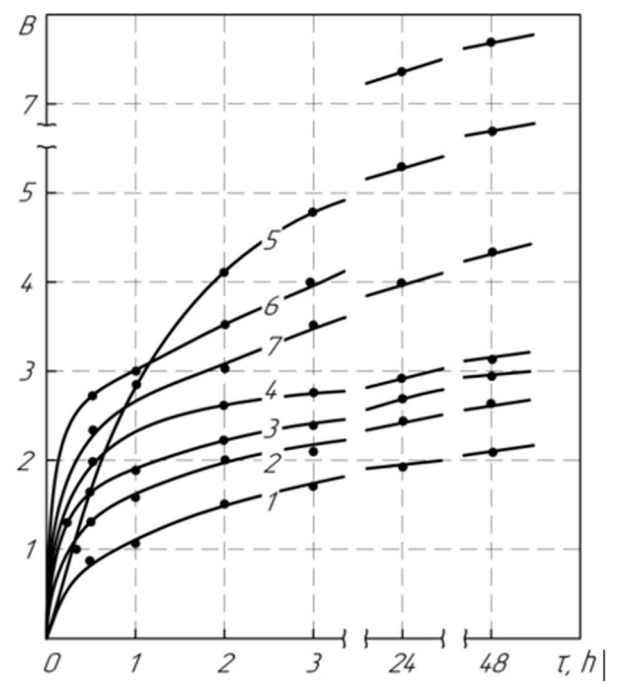

Fig. 1. Kinetics of water absorption $B, \mathrm{~kg} / \mathrm{kg}$ of granulated upper cotton grass-sphagnum peat $\mathrm{R}_{\mathrm{p}}=25 \%$ (1); peat and mineral compositions: peat kaolin clay in proportions 90:10 (2), 85:15 (3), 75:25 (4); upper magellanicum peat $\mathrm{R}_{\mathrm{p}}=5-10 \%$ (5); peat and mineral compositions: peat kaolin clay in proportions $60: 40(6), 50: 50(7)$

Studies on the increase in the pelletizability of peat of various degrees of decomposition in the presence of clay components made it possible to establish that introduction of these additives increases the rate of granule formation and improves their shape. The moisture content of moulding is inversely proportional to the content of mineral components, which makes it possible to reduce the amount of moisture, which evaporates during drying the materials.

When studying the swelling of peat composite sorbents obtained under a "soft" drying regime $\left(T \approx 20^{\circ} \mathrm{C}\right)$, it was found that adding clay allows to obtain an additional volume of absorption as the moisture absorbs. That is, an increased swelling is distinctive for organomineral mixtures compared with the original peat. As follows from the analysis of Figure 2, with the increase of clay content the absorption capacity increases as well, which is due to the increased swelling of the composition. 


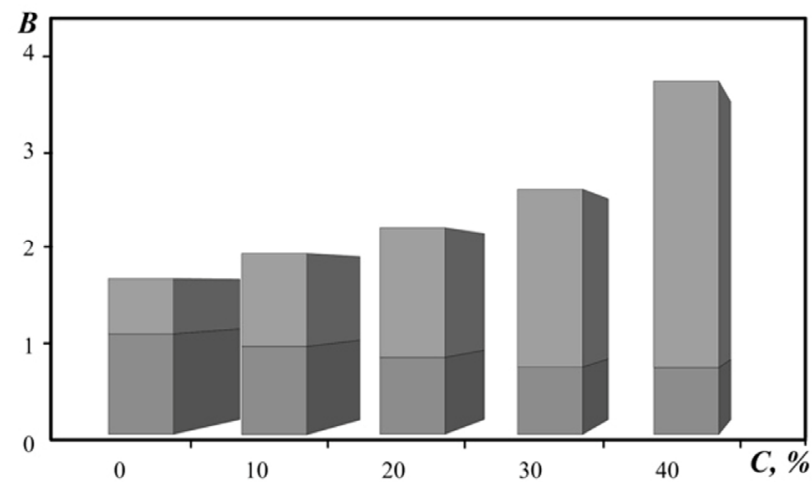

Fig. 2. Initial porosity and increment in pore volume during water absorption by granules (average diameter $5 \mathrm{~mm}$ ) with different content of $C$, \% kaolin clay: initial porosity in the lower part of the diagram, the upper part shows the increment in porosity that occurs when the material swells

Drying is the next step in the preparation of composite moulded sorbents based on peat. The temperature regime of drying should ensure the necessary shrinkage strain (expressed in the density and porosity of the sorbents), as well as the required hydrophilicity or hydrophobicity of the material that determines wettability by various types of liquids. The control of the drying process consists in varying temperature regime, humidity of heat-carrying agent in a drying chamber, processing time, etc. For composite materials (Figure 3), when the drying temperature increases, the moisture absorption decreases, which indicates the initial hydrophobization processes in their structure.

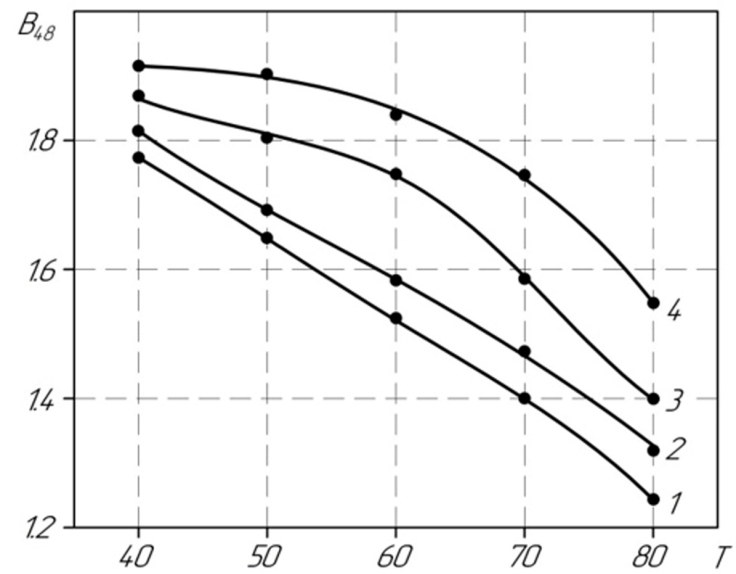

Fig. 3. Dependence of water absorption for 48 hours $\boldsymbol{B}_{48}, \mathrm{~kg} / \mathrm{kg}$ on drying temperature $T,{ }^{\circ} \mathrm{C}$ for peat and mineral compositions with kaolin clay content: 1-10\%, 2-20\%, 3-30\%, 4-40\%

Thermal modification is the final area of the change (if necessary) of the properties of composite sorbents. For peat and organo-mineral mixtures (peat with kaolin clay) it was established that depending on the conditions of thermal treatment materials with different water absorption parameters can be obtained. If the treatment is carried out with oxygen access, then due to the burning out of combustible components a material with a developed porous structure that retains its hydrophilic components is formed.

A study of the water absorption ability of such sorbents indicates an increased capillary absorption of moisture with a limited but stable swelling of the clay components in the modified peat matrix. Thermal treatment of peat and waste products of its production $[15$, 16] with insufficient access of oxygen makes it possible to obtain a hydrophobic material. 
After selective sorption of liquid hydrocarbons, the material forms a stable floating conglomerate that can be easily removed from the surface and sent for processing or incineration. Many analogues [8] often have lower consumer properties (absorption capacity, porosity, biological stability, retention capacity, etc.). In addition, peat properties allow further modification of the sorbent with oil-oxidizing biological products, which will promote rapid destruction of oil products left in the water.

Analysis of the data, obtained for peat materials subjected to heat treatment without access of oxygen, demonstrates that this type of modification increases the sorption capacity for petroleum products by $45-50 \%$ (Table 1 ).

Table 1. Oil capacity of peat sorbents

\begin{tabular}{|l|c|c|c|}
\hline \multicolumn{1}{|c|}{ Material } & $\begin{array}{c}\text { Sorbent capacity of } \\
\text { a source material }\end{array}$ & $\begin{array}{c}\text { Sorbent capacity of a } \\
\text { thermally treated ma- } \\
\text { terial }\end{array}$ & $\begin{array}{c}\text { Change in sorbent } \\
\text { capacity, \% }\end{array}$ \\
\hline Milled peat & $5-5.4$ & $5.8-7.8$ & Increase by $20-45$ \\
\hline Granulated peat & $2.4-2.6$ & $3.3-4$ & Increase by $40-50$ \\
\hline
\end{tabular}

The sorbent has a low density, which allows it to be used for collecting oil during spills on water surface (bulk density of granular peat of low decomposition rate reduces from 120 $\mathrm{kg} / \mathrm{m}^{3}$ to $\left.100 \mathrm{~kg} / \mathrm{m}^{3}\right)$.

\section{Conclusions}

In all cases, modification is possible (thermal, thermochemical, mechanochemical, chemical, electromagnetic, biochemical). It is necessary that attention is paid to the fact that a greater effect is achieved by introducing additional modifying additives that increase wettability, swelling, granulation, porosity, etc. In this case, a transition to composite sorption materials takes place.

Thus, use of the proposed approach makes it possible to comprehensively take into account properties of peat raw materials, extraction technology, possible directions of its processing, requirements to the qualitative characteristics of sorbents, as well as the cost of various options of the final product.

\section{References}

1. P. Bel'kevich, L. Chistova, L. Rogach, M. Sobol, Solid Fuel Chemistry, 14:4, 125-129 (1980)

2. P. Bel'kevich, L. Chistova, L. Rogach, T. Sokolova, Solid Fuel Chemistry, 18:5, 91-95 (1984)

3. Y. Navosha, S. Prokhorov, V. Strigutskiy, A. Tomson, Eurasian Soil Science, 24:5, 1-6 (1992)

4. A. Afanas'ev, Colloid Journal of the Russian Academy of Sciences: Kolloidnyi Zhurnal, 53:3, 425-430 (1991)

5. A. Afanas'ev, A. Boltushkin, Colloid Journal of the Russian Academy of Sciences: Kolloidnyi Zhurnal, 58:2, 139-144 (1996)

6. O. Misnikov, E. Chertkova, Eurasian Mining, 1, 63-68 (2014)

7. A. Afanas'ev, S. Gamayunov, O. Misnikov, Colloid Journal, 61:3, 274-279 (1999)

8. O. Misnikov, A. Timofeev, O. Pukhova, Polymer Science. Series D, 8:1, 66-74 (2015) 
9. N. Gamayunov, B. Maslennikov, Eurasian Soil Science, 24:7, 32-37 (1992)

10. N. Gamayunov, B. Maslennikov, Y. Shul'man, Eurasian Soil Science, 24:4, 122-126 (1992)

11. L. Ansone-Bertina, M. Klavins, Open Chemistry, 14:1, 46-59. (2016)

12. C. Zheng, S. Feng, P. Liu, E. Fries, Q. Wang, Z. Shen, H. Liu, T. Zhang, Clean - Soil, Air, Water, 44:9, 1163-1173 (2016)

13. A. Robalds, L. Dreijalte, O. Bikovens, M. Klavins, Desalination and Water Treatment, 57:28, 13285-13294 (2016)

14. E. Bannova, N. Kitaeva, Solid Fuel Chemistry, 49:6, 377-380 (2015)

15. J. Lee, X. Yang, H. Song, Y. Ok, E. Kwon, Energy, 120, 929-936 (2017)

16. O. Misnikov, Mires and Peat, 18, 1-15 (2016) 
